\title{
Environmental and occupational exposure to toxicants and sperm parameters of men investigated for infertility
}

\author{
Wijesekara GUS ${ }^{1}$, Fernando DMS ${ }^{1}$, Wijerathna ${ }^{2}{ }^{2}$, Bandara $\mathbf{N}^{1}$
}

\begin{abstract}
Objective: The study aimed to determine the association between environmental and occupational exposure to toxicants and semen parameters of men investigated for infertility.
\end{abstract}

Methods: Exposure information was obtained using interviewer administered questionnaire with informed consent. WHO guidelines and cut off values were used in analyzing the sperm parameters. The parametric and non-parametric data were analysed using t- test and chisquare test respectively. Mean semen parameters between groups exposed to different toxicants were compared using one way ANOVA.

Results: In the study population, $53.9 \%$ of men were exposed to toxicants through environmental or occupational sources. Exposures were mainly to petroleum products $(30.2 \%)$, industrial chemicals $(16.9 \%)$ and agrochemicals $(6.8 \%)$. The mean values of sperm concentration, progressive motility, normal forms and viability of subjects exposed to petroleum products were lower compared to non exposed group with significant differences in normal morphological forms [31.1 (18.46)\%] vs. [38.1 (17.90)\%] $(\mathrm{p}=0.02)$ and viability [46.6 $(22.26) \%]$ vs. [55.2 (19.50)\%] ( $p=0.02)$. All the sperm parameters were lower in the exposed group, with a significant difference in sperm morphology [33.5 (17.1)\%] vs. [38.1(17.9)\%] $(p=0.03)$ and sperm viability [49.3 (19.4)\%] vs. [55.2 (19.5)\%] $(p=0.02)$ compared to non exposed group.

Conclusion: Occupational and environmental exposure to reproductive toxicants is associated with poor semen quality with significant reduction in normal forms and viability of sperm.

Keywords: Reproductive toxicants, sperm parameters.

\section{INTRODUCTION}

During the past 50 years, a significant decline in the semen quality has been reported ${ }^{1}$. Occupational exposure to reproductive toxicants, environmental pollutants and life style factors has been explored as possible contributors $^{2}$.

Human exposure to environmental pollutants via one or more routes can impair spermatogenesis in adults leading to reduced sperm quality ${ }^{3}$. Gaseous pollutants such as nitric

\footnotetext{
1 Department of Health Science, Faculty of Medical Sciences, University of Sri Jayewardenepura.

2 University of Colombo
}

\section{Correspondence: G.U.S. Wijesekara}

E-mail: udaya.wije@gmail.com

Competing interests: None oxide, sulphur monoxide, carbon monoxide and heavy metals such as lead and cadmium have been shown to be significantly associated with decreasing semen quality ${ }^{4}$. Occupational exposure to agents such as some solvents, pesticides, petroleum, cement and heat are also known to increase the risk of infertility in men ${ }^{5}$.

Of the many environmental pollutants, toxicity due to heavy metals is known to be enormous and is on the rise globally. Sri Lanka is no exception. Air pollution in cities such as Colombo is a major health hazard. Motor vehicles continue to be the most significant contributor to air pollution. The number of highly polluting diesel vehicles, three wheelers and motor cycles has been increasing nearly threefold during 1990-20006. A recent study has demonstrated the presence of heavy metals in ambient air with much higher levels in Colombo7.
Heavy metals have also been detected in local food items ${ }^{8}$.

It is estimated that about 10 to 12 per cent of married couples in Sri Lanka are sub fertile 9 . A cause of infertility is unknown in many of these couples. Exposure to reproductive toxicants as a result of rapid industrialization, unplanned urbanization and increase in the number of vehicles and transportation could be contributory factors for unknown causes of infertility. Hence this study was planned to determine the association between environmental and occupational exposures to toxicants and semen parameters of men investigated for infertility.

\section{MATERIALS AND METHODS}

\section{Study sample and setting:}

Male partners of couples $(n=295)$ investigated for infertility at a tertiary care centre in Colombo (Vindana Reproductive Health centre) from August 2010 to March 2012 were included in the study. Only men with idiopathic infertility were included in the study.

\section{Data collection:}

Demographic data and the information regarding environmental and occupational exposures were collected using an interviewer administered questionnaire after obtaining informed written consent. Subjects were categorized in to two groups: subjects who were exposed to toxicants either environmentally or occupationally (exposed group) and subjects who were not exposed (non exposed group). Environmentally or occupationally exposed men included those who were exposed to one or more of the following for a period of three months or more

a) those living in areas less than $50 \mathrm{~m}$ from a main road or having 
an industry which was known to emit reproductive toxicants,

b) men reporting contact with chemicals and other potentially hazardous substances at work places such as welding, painting, printing, plumbing and farmers using agrochemicals

c) three wheeler drivers and those who rode motor bicycles more than $40 \mathrm{~km}$ per day.

\section{Seminal fluid analysis:}

Semen samples were collected after a period of 2-7 days of sexual abstinence and was analysed according to the WHO guidelines ${ }^{10}$. When assessing the sperm concentration, motility, viability and morphology the average values of three readings for each semen parameter were taken. If any abnormality was observed in any of the parameters, a second sample was analyzed after seven days. If any discrepancy for any semen parameter was observed between two samples, a third sample was analysed and mean value of each parameter was considered for analysis.

\section{Statistical analysis:}

Statistical analysis was done using SPSS (version16). Means of sperm parameters of exposed and non exposed groups were compared using independent sample t-test. $\mathrm{P}<0.05$ was considered as significant. The frequencies of normal and abnormal sperm parameters between exposed and non exposed groups and the frequency of geographical distribution of urban, rural and suburban population between exposed an nonexposed groups were compared using chi-square test. One way ANOVA was used to compare mean semen parameters between exposure to different toxicants.

Ethical clearance was obtained from Faculty of Medical Sciences, University of Sri Jayewardenepura, Sri Lanka.

\section{RESULTS}

Demographic data and geographic distribution according to exposure:

The age, body mass index, duration

\begin{tabular}{|llllc|}
\hline \multicolumn{4}{|c|}{ Table 1. Demographic characteristics of exposed and non exposed groups } \\
\hline \multicolumn{1}{|c|}{ Characteristic } & $\begin{array}{c}\text { Total } \\
(\mathbf{n}=295)\end{array}$ & $\begin{array}{c}\text { Exposed } \\
(\mathbf{n}=159)\end{array}$ & $\begin{array}{c}\text { Not exposed } \\
(\mathbf{n = 1 3 6 )}\end{array}$ & ${ }^{*} \mathrm{p}$ value \\
\hline Age(Years) & $34.8(5.3)$ & $34.6(5.3)$ & $34.9(5.4)$ & 0.6 \\
\hline $\begin{array}{l}\text { Body Mass Index } \\
(\mathrm{kg} / \mathrm{m} 2)\end{array}$ & $24.4(4.3)$ & $23.8(3.7)$ & $25.1(4.8)$ & 0.1 \\
\hline $\begin{array}{l}\text { Duration of } \\
\text { Infertility(months) }\end{array}$ & $45.5(35.1)$ & $47.3(35.6)$ & $43.3(34.5)$ & 0.3 \\
\hline *independent sample t-test & & & \\
\hline
\end{tabular}

Table 2. Geographical distribution of exposed and not exposed men $(n=295)$

\begin{tabular}{|lccc|}
\hline \multicolumn{1}{|c}{ Area } & Total $(\%)$ & Exposed $(\%)$ & Not exposed $(\%)$ \\
\hline Urban $(n=77)$ & 26.1 & 12.5 & 13.6 \\
\hline Suburban $(n=139)$ & 47.1 & 25.8 & 21.3 \\
\hline Rural $(n=79)$ & 26.8 & 15.6 & 11.2 \\
\hline${ }^{*}$ chi-square $=1.6, d f=2 \quad p=0.4$ & & & \\
\hline
\end{tabular}

of infertility and geographical distribution were similar in exposed and not exposed groups (Table 1).

There was no significant difference in percentage of men living in urban, suburban and rural areas among exposed and non exposed men (Table 2).

\section{Semen characteristics of the study population:}

Of the men investigated for infertility $67 \%$ were normozoospermics. As a singleabnormality asthenozoospermia was the commonest and the distribution of other abnormalities are shown in Figure 1. The categorization into normozoospermics and other abnormal forms were done according to WHO guidelines of 2010 where only sperm count, progressive motility and morphology are considered ${ }^{10}$. However in this study viability of exposed and not exposed groups was compared as sperm viability is a clinically important parameter.

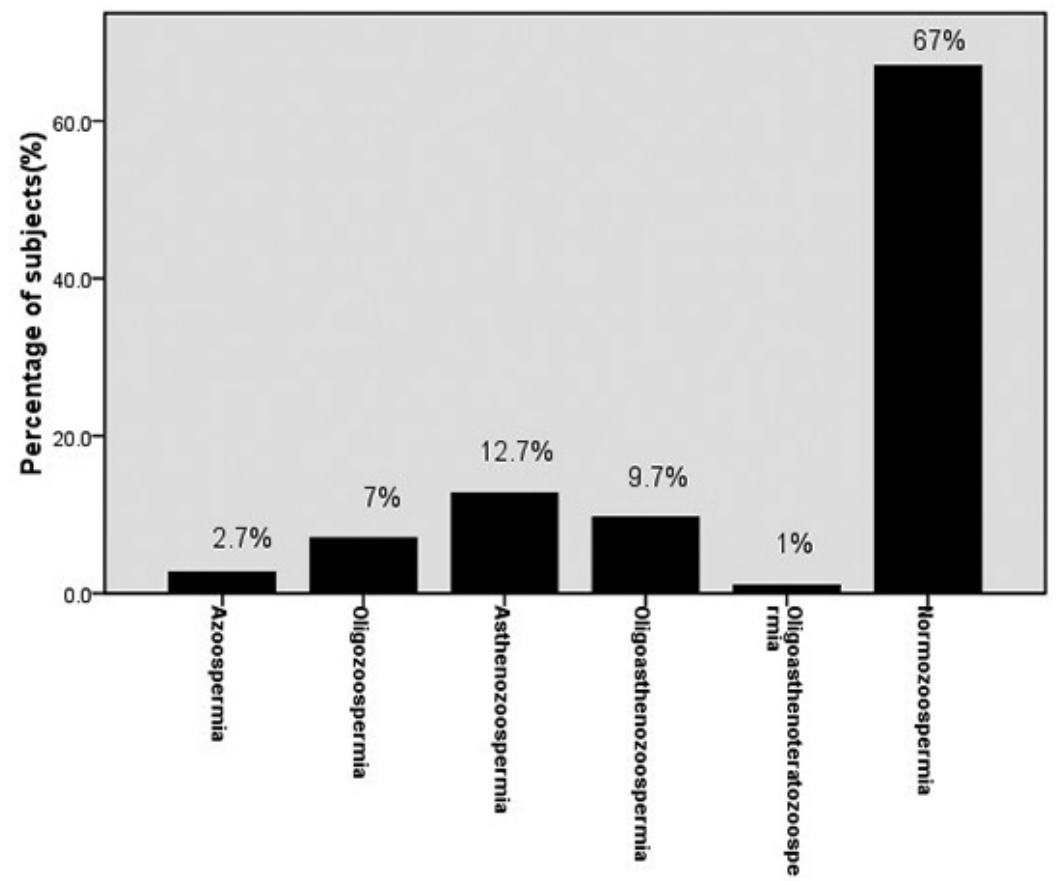

Fig.1 Distribution of different sperm abnormalities. 


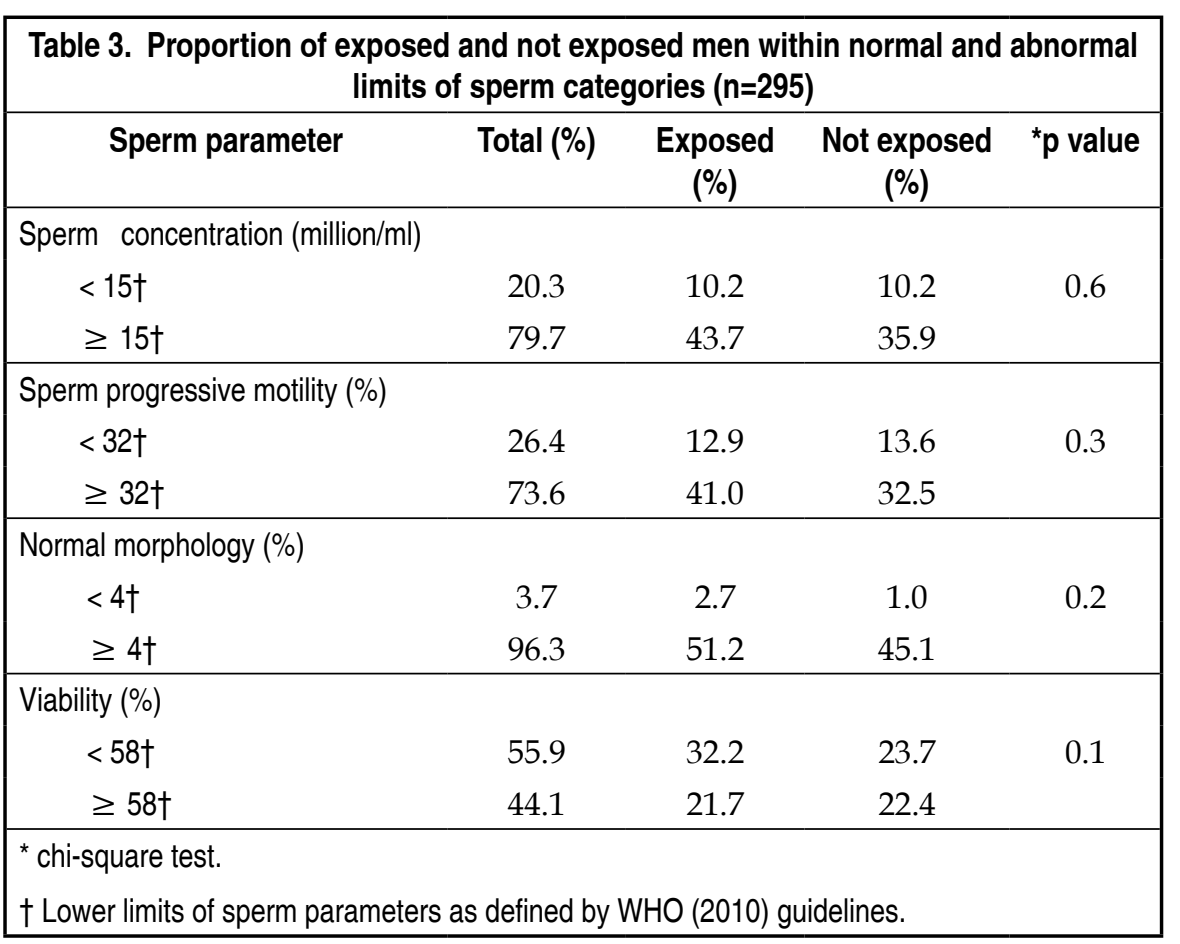

\begin{tabular}{|lccc|}
\hline \multicolumn{3}{|c|}{ Table 4. Sperm parameters of exposed and not exposed men } \\
\hline $\begin{array}{c}\text { Sperm parameter } \\
\text { [Mean(SD)] }\end{array}$ & $\begin{array}{c}\text { Exposed } \\
\text { (Environmentally } \\
\text { or Occupationally) } \\
\mathrm{n}=159\end{array}$ & $\begin{array}{c}\text { Not exposed } \\
\text { (Environmentally } \\
\text { or occupationally) } \\
\mathrm{n}=136\end{array}$ & P value \\
\hline $\begin{array}{l}\text { Sperm concentration } \\
\text { (million/ml) }\end{array}$ & $54.8(45.5)$ & $63.0(46.1)$ & 0.8 \\
\hline Progressive motility\% & $40.2(18.3)$ & $41.5(18.8)$ & 0.6 \\
\hline Normal forms\% & $33.5(17.1)^{*}$ & $38.1(17.9)$ & 0.03 \\
\hline Viability\% & $49.3(19.4)^{*}$ & $55.2(19.5)$ & 0.02 \\
\hline${ }^{*} \mathrm{p}<0.05$ independent sample t-test & & \\
\hline
\end{tabular}

The table 3 shows the proportion of men exposed and not exposed under each parameter. The values given for each sperm parameter is the $\mathrm{WHO}$ cut off value ${ }^{10}$.

The means of sperm concentration, progressive motility, normal morphological forms and sperm viability of exposed men were lower when compared to men not exposed through environmental or occupational sources with a significant reduction in sperm morphology $(\mathrm{p}=0.03)$ and sperm viability $(\mathrm{p}=0.02)$. (Table 4).

Exposure to one or more of the toxicants such as petroleum products, industrial wastes, agrochemicals and heat was evident in $54 \%(n=159)$ of which the highest exposure (30.2\%) was for petroleum products followed
$29 \%$ were men living in less than $50 \mathrm{~m}$ from a main road and $20 \%$ were men working in industries directly in contact with petroleum products.

The mean values of sperm concentration, progressive motility, normal forms and viability of subjects exposed to petroleum products were lower compared to non exposed group with significant differences in normal morphological forms $(\mathrm{p}=0.02)$ and viability $(\mathrm{p}=0.02)$ (Table 5$)$.

\section{DISCUSSION}

The aim of this study was to assess the association between environmental or occupational exposures to reproductive toxicants and the sperm parameters of men investigated for infertility. Exposure to a particular reproductive toxicant for duration of 3 months or more was considered as a positive exposure in this study.

Most studies conducted on reproductive toxicants and sperm parameters, vary with regards to the types of exposures, the study populations and the method of assessment of exposure. Hence the reported findings differ. However, findings similar to the current study with a lower means in sperm concentration, progressive motility, normal morphology and viability of environmentally or occupationally exposed men when compared to the non exposed with a significant reduction in sperm morphology ${ }^{11}$ and viability ${ }^{12}$ had been reported by others. Some studies also report a significant reduction in sperm concentration ${ }^{11}$ and in sperm motility ${ }^{13}$ in the exposed osed to petroleum products ( $51 \%$ were three wheeler drivers, by industrial chemicals $(16.9 \%$ agrochemicals which included pesticides and fertilizers (6.78\%) and heat $(0.3 \%)$. Of those who were

Table 5 . Mean sperm parameters an

\begin{tabular}{|lcccc|}
\hline \multicolumn{4}{|c|}{ Table 5. Mean sperm parameters and exposure to different toxicants } \\
\hline \multicolumn{1}{|c|}{ Sperm parameter } & $\begin{array}{c}\text { Exposure to } \\
\text { agrochemicals } \\
(\mathrm{n}=20)\end{array}$ & $\begin{array}{c}\text { Exposure } \\
\text { to Industrial } \\
\text { chemicals } \\
(\mathrm{n}=50)\end{array}$ & $\begin{array}{c}\text { Exposure to } \\
\text { petroleum } \\
\text { products } \\
(\mathrm{n}=89)\end{array}$ & $\begin{array}{c}\text { Not exposed } \\
(\mathrm{n}=136)\end{array}$ \\
\hline $\begin{array}{l}\text { Sperm concentration } \\
\text { (million/ml) }\end{array}$ & $60.9(58.92)$ & $72.7(60.95)$ & $55.1(52.30)$ & $63.0(46.1)$ \\
\hline $\begin{array}{l}\text { Sperm progressive } \\
\text { motility (\%) }\end{array}$ & $42.4(17.85)$ & $44.1(14.31)$ & $38.1(19.96)$ & $41.5(18.8)$ \\
\hline Normal forms (\%) & $33.0(12.64)$ & $38.7(15.40)$ & $31.1(18.46)^{*}$ & $38.1(17.9)$ \\
\hline Viability (\%) & $56.4(15.40)$ & $52.6(13.65)$ & $46.6(22.26)^{*}$ & $55.2(19.5)$ \\
\hline${ }^{*} p<0.05$ One way ANOVA. & & & \\
\hline
\end{tabular}


group. In the present study the sperm concentration and progressive motility were similar in the exposed and the unexposed groups and the possible reason for this could be the short duration of exposure ${ }^{14}$, or a low level exposure ${ }^{15}$ as reported by other investigators. The total duration of exposure however was not analysed in the present study.

In this study one third of the men were exposed to petroleum products and out of them, $51 \%$ were three wheeler drivers who were regularly exposed to diesel or petroleum exhaust fumes. The sperm concentration, progressive motility, normal morphology and viability were reduced in men exposed to petroleum products with significant reductions in normal morphology and viability. Similar results have been reported in a study done in Italy among taxi drivers ${ }^{16}$ and in Iran where significant reductions in sperm morphology and motility have been reported among men engaged in transportation ${ }^{17}$. Lead is probably the most common potential reproductive toxicant present in the environment in high concentrations due to use of petroleum products ${ }^{18}$. Although unleaded petroleum has been used in Sri Lanka, the lead concentration in air, water and soil have been reported to be high, possibly due to other sources of pollution ${ }^{19}$.

In the present study $6.8 \%$ of men were exposed to agrochemicals possibly due to use of insecticides, pesticides or fertilizer. There was no significant difference in sperm parameters between men exposed to agrochemicals when compared to the not exposed and these findings are similar to those reported by Larsen et $a l^{20}$. The concentrations of cadmium and other heavy metals such as Se (selenium), Mo (molybdenum), U (Uranium) in the soil and ground water in areas where inorganic fertilizer and pesticides have been used for agriculture have been reported to be high $^{21,22}$. Bandara et al., also report that poor de-silting of reservoirs could lead to progressive rise in cadmium levels in water which in turn feed the paddy cultivation ${ }^{22}$.

In the current study, the possible known causes of infertility were excluded. Hence it is likely that environmental and occupational exposures to reproductive toxicants could be an aetiological factor for infertility in this group of men. Heavy metals such as lead and cadmium are potential elements that disrupt the neuroendocrine secretion of reproductive hormones or act directly at testicular tissue and damage spermatogenesis. Furthermore, lead exposure has been linked with chromosomal aberrations. Both animal experiments and human studies suggest that the sperm chromatin structure is altered at low exposure ${ }^{23}$. A possible explanation for this structural damage is that lead and other cations like mercury and copper may cause a partial replacement of zinc which is essential for sperm head chromatin stabilization. Failure of delay in sperm chromatin decondensation may lead to decreased fertility or different kinds of DNA damage in the fertilization process $^{23}$. Lead and cadmium are also known to hinder sperm functions such as acrosome reaction and fertilization $^{24}$. Therefore even when the findings of routine investigations are normal, the failure of fertilization could be due to exposure to reproductive toxicants which need to be explored in the presence of evidence of exposure. In conclusion occupational and environmental exposure to reproductive toxicants is associated with poor semen quality with significant reduction in normal forms and viability of sperm. Petroleum products seem to have a negative effect on sperm parameters with a significant negative effect on sperm morphology and viability.

\section{ACKNOWLEDGMENT}

University of Sri Jayewardenepura, for the research Grant (ASP/06/P/ SCI/2011/12).

\section{REFERENCES}

1. Carlsen E, Giwercman A, Keiding N, Skakkebaek NE. Evidence for decreasing quality of semen during past 50 years. BMJ 1992; 305: 609-13.
2. Ten J, Mendiola J, Alberto M, Torres-Cantero AM, Jose M, Moreno-Grau S, Roca M, Romero J, and Bernabeu R. Occupational and lifestyle exposures on male infertility: A mini review. The Open Reproductive Science Journal 2008; 1: 16-21.

3. Sharpe RM. Environmental/ lifestyle effects on spermatogenesis. Phil Trans 2009; 365: 1697-1712.

4. Pant N, Upadhyay G, Pandey S, Mathur S, Saxena DK, Srivastava SP. Lead and Cadmium concentrations in the Seminal plasma of men in general population: Correlation with sperm quality. Reprod Toxicol 2003; 17: 447-50.

5. Inhorn MC, King L, Nriagu JO, Kobeissi L, Hammoud N, Awwad J, Abu-Musa AA, Hannoun AB. Occupational and environmental exposures to heavy metals: Risk factors for male infertility in Lebanon? Reprod Toxicol 2008; 25: 203-12.

6. Illeperuma OA. Environment pollution in Sri Lanka: a review. J Natn Sci Foundation Sri Lanka 2000; 28(4): 301-325.

7. Gunathilaka PADHN, Ranudeniya RMNS, Najim MMM, Seneviratne S. A determination of air pollution in Colombo and Kurunegala, Sri Lanka using energy dispersive X-ray fluorescence spectrometry on Heterodermia speciosa. Turkish J of Botany 2011; 35: 439-446.

8. Weerasinghe LSA, Manage PM. Determination of lead and cadmium concentrations in some leafy vegetables. 2005; 61st Annual sessions of SLAAS, Colombo.

9. Ministry of Health, Population division, Nutrition and Welfare, Colombo, Sri Lanka. Report on the Fifth Asian and pacific population conference, Bangkok, Thailand, Sri Lanka, country report. December 2002.

10. World Health Organization. Laboratory Manual for the Examination and processing of 
the human semen. 5th Edition, WHO Press, Geneva, Switzerland. 2010.

11. Abell A, Ernst E, Bonde JP. Semen quality and sexual hormones in greenhouse workers. Scand J Work Environ Health 2000; 26: 492-500.

12. Danadevi K, Rozati R, Reddy PP, Grover P. Semen quality of Indian welders occupationally exposed to nickel and chromium. Reproductive Toxicology. 2003; 17: 451-456.

13. Padungtod C, Savitz DA, Overstreet JW, Christiani DC, Ryan LM, Xu X. Occupational pesticide exposure and semen quality among Chinese workers. J Occup Environ Med 2000; 42: 982992.

14. Aribarg A, Sukchareon N. Effects of occupational lead exposure on spermatogenesis. J Med Assoc Thailand. 1996; 79: 91-97.

15. Hovatta O, Venalainen EJ, Kuvsimaki L, Heikkila J, Hirvi $\mathrm{T}$, Reima I. Aluminium, lead and cadmium concentrations in seminal plasma and spermatozoa, and semen quality in finnish men. Human Reproduction. 1998; 13(1): 115-119.
16. Figà-Talamanca I, Cini C, Varricchio GC, Dondero F, Gandini L, Lenzi A, Lombardo F, Angelucci L, Di Grezia R, Patacchioli FR. Effects of prolonged autovehicle driving on male reproduction function: a study among taxi drivers. Am J Ind Med 1996; 30(6): 750-758.

17. Vaziri MH, Gilani MAS, Kavousi A, Firoozeh M, Jazani RK, Dizaj AVT, Mohseni H, Lankarani NB, Azizi M, Yazdi RS. The Relationship between Occupation and Semen Quality. International Journal of Fertility and Sterility 2011; 5(2): 66-71.

18. Hutton M, Symon C. The quantities of cadmium, lead, mercury and arsenic entering the UK environment from human activities. Science of the Total Environment. 1986; 57:129-150.

19. Bandara JMRS, Senevirathna DMAN, Dasanayaka DMRSB, Herath V, Bandara JMRP, Abeyasekara T, Rajapaksha KH. Chronic renal failure among farm families in cascade irrigation system in Sri Lanka associated with elevated dietary cadmium levels in rice and freshwater fish (Tilapia). Environ Geochem Health.
2008; 30: 465- 478.

20. Larsen SB, Giwerkman A, Spano $\mathrm{M}$, Bonde JP, Asclepios T. A longitudinal study of semen quality in pesticide spraying Danish farmers. Reprod Toxicol 1998; 12(6): 581-589.

21. Gimeno-Garcia E, Andrew V, Boluda R. Heavy metals incidence in the application of inorganic fertilizers and pesticides to rice farming soils. Environ Pollut 1996; 92(1): 9-25.

22. Bandara JMRS, Wijewardena HVP, Liyanage J, Upul MA, Bandara JMUA. Chronic renal failure in Sri Lanka caused by elevated dietary cadmium: Trojan horse of the green revolution. Toxicol Lett 2010; 198(1): 33-39.

23. Johansson L, Pelliciari CE. Lead-induced changes in the stabilization of the mouse sperm chromatin. Toxicology 1988; 51: 11-24.

24. Benoff S, Jacob A, Hurley R. Male infertility and environmental exposure to lead and cadmium. Human Reproduction Update. 2000; 6(2): 107-121 